\title{
Internet research: Self-monitoring and judgments of attractiveness
}

\author{
TOM BUCHANAN \\ University of Sunderland, Sunderland, England
}

\begin{abstract}
Two studies examined the relationship between self-monitoring and factors influencing romantic attraction to others. In Study 1, participants completed an Internet-mediated version of the SelfMonitoring Scale (Gangestad \& Snyder, 1985) and indicated which of two people (one physically attractive, one with a more desirable personality) they found most attractive. Results matched previous findings (Snyder, Berscheid, \& Glick, 1985), but the effect was smaller. Study 2, a paper-and-pencil replication of Study 1, examined whether the weaker effect was due to Internet mediation and found no differences in the choices made by high and low self-monitors. Results suggested that while determinants of attraction may vary for different populations, Internet research methods can tap the same phenomena as traditional laboratory studies.
\end{abstract}

It is fast becoming a cliché to write that the potential of the Internet as a medium for psychological research is increasingly being recognized and harnessed. There are compelling reasons for doing such work (e.g., Buchanan \& Smith, 1999b; Hewson, Laurent, \& Vogel, 1996; Reips, 1996, 2000; Schmidt, 1997; Smith \& Leigh, 1997; Szabo \& Frenkl, 1996), and various traditional empirical protocols are being adapted for use on the Internet (e.g., Birnbaum, 1999; Joinson, 1999; Krantz, Ballard, \& Scher, 1997; Pagani \& Lombardi, 2000; Pasveer \& Ellard, 1998; Schwarzer, Mueller, \& Greenglass, 1999; Smith \& Leigh, 1997; Stones \& Perry, 1997). However, numerous potential problems for the validity of such work have been also identified (e.g., Buchanan \& Smith, 1999b; Schmidt, 1997).

For this reason, a number of validation studies have been published (e.g., Buchanan \& Smith, 1999a, 1999b; Krantz et al., 1997; Pasveer \& Ellard, 1998), and more still are in progress. At this point in time, findings seem in general to show that Internet-mediated studies do address the same psychological phenomena and produce the same patterns of results as their traditional counterparts (e.g., Joinson \& Buchanan, in press; Krantz et al., 1997; Krantz \& Dalal, 2000; Smith \& Leigh, 1997).

\section{WWW-Mediated Personality Tests}

One research instrument that readily lends itself to electronic implementation is the questionnaire-based personality test. It is relatively easy to construct WWW-based instruments (e.g., Birnbaum, 2000; Schmidt, 1997) that can make the process of test administration and scoring largely automatic.

A portion of the results of Study 1 was presented at the Society for Computers in Psychology meeting in Dallas, Texas, November 1998. Correspondence should be sent to T. Buchanan, Department of Psychology, University of Westminster, 309 Regent St., London WI R 8AL, England (e-mail: tb99@iname.com).
There are many reasons why one would wish to do this - for instance, the possibility of access to a large number of participants; the virtual automation of webmediated studies; and savings of time, money, and laboratory space (Musch \& Reips, 2000, report that the factors rated most important by people actually involved in Web research were sample size and resulting statistical power, the relative speed of Internet research, and access to participants from other countries). As well as such practical motivations, there are psychologically oriented reasons for doing research involving personality scales on the Internet.

Among these is the "candor hypothesis"- the idea that on-line participants are more candid and more willing to disclose self-relevant information. There is evidence that increased self-disclosure may be found with stand-alone computerized tests (e.g., Levine, Ancill, \& Roberts, 1988), although the effect may be mediated by individual differences in respondents (Rosenfeld et al., 1991). There are reasons to believe that this effect extends to Webmediated instruments. For example, Stones and Perry (1997) found their respondents willing to disclose highly personal information; Davis (1999) found that WWW respondents reported higher levels of self-focused negative thought than did a sample tested in a classroom setting; and Joinson (1999) found that WWW participants responded to a questionnaire in a less socially desirable fashion. Reasons advanced for this include the anonymity of participants (Hewson et al., 1996) and the "disinhibited" nature of on-line behavior (e.g., Joinson, 1998).

It has also been argued (Reips, 2000) that Web studies may have higher ecological validity than laboratory equivalents. More detailed discussions of these and other advantages of WWW research are presented in reviews by, among others, Reips (2000) and Buchanan (2000).

However, the validity of Internet-mediated research has yet to be fully explored. In the case of WWW personal- 
ity tests, an obvious question to ask is whether such instruments are psychometrically and psychologically equivalent to traditional pencil-and-paper measures (Buchanan \& Smith, 1999b).

The (limited but accumulating) evidence thus far would seem to indicate that they can be. Pasveer and Ellard (1998) have shown that an entirely new and psychometrically satisfactory Internet-mediated test (of self-trust) may be developed. Davis (1999) assessed the equivalence of Webmediated and traditional implementations of a scale measuring self-focused rumination and found satisfactory indices of reliability for both. Schwarzer et al. (1999) found similar psychometric properties and associations with other variables in WWW and traditional versions of a selfefficacy scale. Evidence for the psychometric equivalence of electronic and paper-and-pencil versions of a wellestablished personality measure has also been presented in work by Buchanan and Smith (1999a, 1999b).

\section{Self-Monitoring}

The measure explored by Buchanan and Smith (1999a, $1999 \mathrm{~b}$ ) is Gangestad and Snyder's (1985) measure of the trait of self-monitoring, the revised Self-Monitoring Scale (SMS-R). The term self-monitoring refers to people's capacity and tendency to observe and regulate their expressive behaviors and self-presentation. Individuals high in self-monitoring are typically sensitive to social and situational cues, and they adjust their behavior accordingly. Low self-monitors, on the other hand, lack either the ability or the motivation to do this, and they tend to behave in ways consistent with stable personality attributes or internal states (Snyder \& Gangestad, 1986).

The SMS-R is a revised version of Snyder's (1974) original measure of self-monitoring, which has been described as "the most popular individual differences measure associated with impression management and selfpresentation" (Rosenfeld et al., 1991, p. 27). It consists of 18 true/false items and has satisfactory and wellestablished psychometric properties (Gangestad \& Snyder, 1991). The SMS-R has been implemented as a WWW-mediated test in which the items are presented as an HTML form, which, once completed, is automatically scored by CGI scripts. The psychometric properties of the WWW and paper versions of the test appear to be equivalent (Buchanan \& Smith, 1999b), and there is some evidence for the construct validity of the WWW version of the scale (Buchanan \& Smith, 1999a, found that it differentiated between groups of respondents believed to differ in self-monitoring tendencies). Further confirmation that it really does measure self-monitoring can only come from evidence that empirical findings obtained with the instrument are consistent with theoretical analyses of self-monitoring.

\section{Self-Monitoring and Determinants of Attractiveness}

It is known that high and low self-monitors differ in the value they place on various determinants of attractive- ness in others. High self-monitors place more emphasis on exterior characteristics, such as physical appearance, whereas low self-monitors attach more importance to internal characteristics (Snyder, 1987).

Snyder, Berscheid, and Glick (1985) gave 39 male undergraduates the opportunity to examine dossiers containing information about potential dating partners prior to choosing which one they would like to meet for a coffee in the University cafeteria. They found that high selfmonitors spent more time examining information about physical attractiveness of potential partners, whereas low self-monitors spent more time examining information about personality traits. In a second study, 32 male undergraduates were required to make a choice between two potential dating partners: one who was physically attractive but had undesirable personal attributes, and one who was physically unattractive but had desirable personal attributes. It was found that high self-monitors were more likely to choose the partner with the attractive face, whereas low self-monitors were more likely to choose the partner with the more desirable personality.

Theoretically consistent findings were reported by Glick (1985), who gave 25 high- and 25 low-self-monitoring men the choice of interacting with potential partners in romantic or nonromantic situations. Among high selfmonitors, the probability of choosing a romantic situation in which to interact was more influenced by the partners' physical attractiveness, whereas low self-monitors were more influenced by personality descriptions.

Glick, DeMorest, and Hotze (1988) found that these tendencies extend to judgments of other people: High self-monitors paid more attention to similarities of physical attractiveness when assessing the compatibility of couples as romantic partners; low self-monitors placed more emphasis on similarity in personality traits. The phenomenon is also seen in areas other than romantic attraction. For instance, Snyder, Berscheid, and Matwychuk (1988) found the same effect influenced decisions about personnel selection: High self-monitors were influenced more by physical appearance than by personal dispositions that would actually affect suitability for the job; for low self-monitors, this pattern was reversed. DeBono and Snyder (1989) found that decisions about consumer products were similarly affected: High self-monitors judged products that were attractive as being of higher quality, whereas low self-monitors judged less attractive but more functional products as being of higher quality.

There does therefore seem to be support for Snyder's (1987) claim. However, the studies from which the most compelling evidence comes (Glick, 1985; Snyder et al., 1985) are compromised in one major respect: They are based on small numbers of male participants. While the studies reported by Glick et al. (1988), Snyder et al. (1988), and DeBono and Snyder (1989) used both male and female participants, suggesting that the effect operates for women as well as men, they did not directly address interpersonal attraction. The effect of self-monitoring on determinants of interpersonal attraction has thus been es- 
tablished only for male heterosexual students. Do the selfmonitoring tendencies of the rest of the population similarly influence whom they are attracted to?

\section{Purpose of Present Research}

It appears that a replication including members of other gender/sexuality groups would be useful and would indicate whether or not Snyder's claim can be generalized to a wider population. It has been suggested (e.g., Smith \& Leigh, 1997) that the Internet is a good medium for recruiting members of such groups (see also McKenna \& Bargh, 1998). Even were this not the case, an Internet replication might be advantageous: Reips (2000) has argued that the findings of Web experiments may, due to the greater demographic diversity of participants, be more generalizable than those of conventional laboratory studies that have traditionally (e.g., McNemar, 1946) used students as participants (and still do today; Banyard \& Hunt, 2000; Reips, 2000).

The issue of attractiveness and the factors that affect it has already received attention from Internet-oriented researchers: Krantz et al. (1997) found that the factors that determine attractiveness of females are very much the same in Web-based replications of laboratory studies. It therefore seems likely that the previously identified effect of self-monitoring on attraction would be observed in Internet samples. The purpose of the present study was thus to test the prediction that high self-monitors will tend to place more weight on physical factors when making decisions about the attractiveness of a potential partner. A subsidiary aim was to gather data on people's reasons for participating in Internet research.

\section{STUDY 1}

\section{Method}

Materials. Grayscale images of 5 male and 5 female faces drawn from the University of Stirling PICS image database (http://pics. psych.stir.ac.uk/index.html) were rated on 7-point scales for physical attractiveness by 12 raters, who were a heterogeneous mix of psychology students and academic and support staff ( 5 men and 7 women). A two-way mixed (face rated $\times$ sex of rater) analysis of variance found a significant main effect for the repeated measures (face rated) factor $[F(1,10)=90.35, p<.0005]$. The ratings assigned by males and females did not differ $[F(1,10)=0.71, p>$ 0.418 , and there was no significant interaction between the two factors $[F(1,10)=0.01, p>.915]$.

The male faces with the highest $(M=5.33, S D=0.98)$ and lowest $(M=1.56, S D=0.67)$ mean ratings were compared using paired $t$ tests and found to differ significantly $[t(11)=10.09, p<$ $.0005]$. Similarly, the female faces with highest $(M=5.33, S D=$ $0.65)$ and lowest $(M=2.75, S D=1.06)$ mean ratings differed significantly $[t(11)=6.20, p<.0005]$. These two pairs of faces were thus selected for use in the study. The mean differences in rated attractiveness were 3.75 and 2.58 , respectively-values similar to those obtained by Glick (1985) and Snyder et al. (1985; Snyder et al., 1988), all of whom used the same rating procedure and found mean differences of $3.9,3.0$, and 2.6, respectively. Male and female raters did not differ significantly in their ratings of the four faces.

Names were assigned to the four faces as follows: The more attractive male face was dubbed "John"; the less attractive male face was dubbed "Chris"; the more attractive female face was dubbed
"Jennifer"; the less attractive female face was dubbed "Kristen" (cf. Snyder et al., 1985). Short "personality profiles" to be paired with these images were generated using the desirable and undesirable personality trait descriptors used by Snyder et al. (1985) and Glick (1985). The same descriptions were used for male and female faces. The description incorporating desirable traits read:

Kristen is highly sociable and outgoing, with a good ability to interact with others. She is open and honest, willing to listen to others and is concerned with getting along with people. She has a stable, easygoing disposition and values her sense of humor very highly.

The description that incorporated undesirable traits read:

John has a reserved attitude toward strangers and is more comfortable with close friends. He is more concerned with himself than with other people. He exhibits a tendency toward moodiness and can react emotionally to events.

Procedure. The participants were recruited via a number of Usenet newsgroups likely to be read by people varying in gender and sexual orientation (these included newsgroups catering specifically for gay men and lesbians). Rules of "netiquette" were strictly observed, and a procedure was adopted whereby no further postings were made to a group if a single person voiced a complaint.

Recruitment notices posted to these newsgroups included a link to a WWW page bearing details about what the experimental procedure entailed. The participants were required to select a link indicating that they understood and consented to the procedure. Once this was done, they were presented with the electronic version of the SMS-R, as previously used by Buchanan and Smith (1999a, $1999 \mathrm{~b}$ ). In addition to the 18 items of the SMS-R, the participants were also asked to indicate their age and gender and to indicate whether they were primarily attracted to males or females.

Those who indicated that they were attracted to females were then presented with a screen on which the faces of "Jennifer" and "Kristen" were shown side by side. Below each image was the appropriate "personality profile." The participants were asked to indicate which of the two they would be most attracted to in a romantic sense. Those who had indicated that they were attracted to men saw an equivalent screen bearing the images and descriptions of "Chris" and "John."

Having chosen, the participants then saw a debriefing screen thanking them for their help and giving a date when they could return to the Website for a summary of the results of the study. At this point, they were also asked to indicate, in free text entry boxes, (1) why they had chosen to take part in the study and (2) any other comments they had. Those who submitted comments were again thanked.

Participants. There were 380 responses to the request for participation. Of these, 44 were deemed invalid (duplicate submissions coming from the same Internet address; Buchanan \& Smith, 1999b; Reips, 2000) and deleted. Of the remaining 336, 16 completed the SMS-R but did not make a choice. A total of 320 participants thus completed the study.

Of the 183 men in the sample, 136 indicated that they were predominantly attracted to women and 47 indicated that they were predominantly attracted to men. ${ }^{1}$ Among the 137 women, 53 were attracted to men and 84 were attracted to women. Mean age was 31.54 years $(S D=10.0)$, and mean self-monitoring score was 9.20 $(S D=3.76)$-figures almost identical to those for the Internet sample reported by Buchanan and Smith (1999b).

\section{Results and Discussion}

The participants were classified as high or low selfmonitors by reference to norms based on the Internet sample obtained in this study and that of Buchanan and Smith (1999b) - a combined $N$ of 1,299. As suggested by Snyder (1987), those scoring in the top quartile (approximated by 12 and above, $20.8 \%$ scored in this range) 
were classified as high self-monitors. Those in the bottom quartile (approximated by 6 and below, $24.2 \%$ scored in this range) were classified as low self-monitors. Selfmonitoring scores for men and women did not differ significantly $[t(1,297)=0.23, p>.81]$, so the same cut-off points were used for both sexes.

Using these criteria, 98 high and 74 low self-monitors were identified in the present sample, and their choices of target were compared. To maximize comparability of findings, the same analysis as used by Snyder et al. (1985) - a $z$ test for proportions - -was used. As hypothesized, the proportion of each group choosing each target differed significantly $(z=1.80, n=172, p<.036$, one-tailed) in the predicted manner: High self-monitors showed a very slight tendency to choose the target with the more attractive face but less attractive personality $(53 \%)$, whereas low self-monitors tended to choose the target with the less attractive face but more attractive personality $(61 \%)$.

It was suggested above that the effect of self-monitoring on attraction had been established only for male heterosexual students. This result suggests the effect is more widely applicable. However, the possibility remains that this is too sweeping a generalization: Are all groups likely to behave in the same way?

There is evidence, for instance, that men and women (e.g., Pines, 1998) and people of different sexualities (e.g., Gonzales \& Meyers, 1993; Siever, 1994) may vary in the importance they place on particular determinants of attractiveness. Would self-monitoring have the same effect for all groups?

In particular, it has been suggested (Siever, 1994) that gay men and heterosexual women (i.e., those groups attracted to males) are concerned with physical attractiveness to a greater degree than are heterosexual men and lesbians (i.e., those groups attracted to females). As a preliminary investigation of this issue, the analysis was repeated for these two subsamples: those attracted primarily to men and those attracted primarily to women. The former group comprised 37 high and 21 low self-monitors. The proportions of high and low self-monitors choosing each target did not differ significantly $(z=0.87, n=58$, $p>.38$ ). The latter group comprised 61 high and 53 low self-monitors. Again, the proportions of each choosing each target did not differ significantly $(z=1.42, n=$ $114, p>.16)$.

However, for the latter group, examination of the proportions making each choice suggested that there might be an effect within the low-self-monitoring group (among whom 19 chose the facially attractive target and 34 chose the less attractive target) that did not operate among the high self-monitors (for whom the numbers choosing each target were 30 and 31 , respectively). A binomial test indicated that among low self-monitors attracted to women the proportions of people choosing each target were significantly different $(z=-2.06, n=53, p<.039)$.

Responses to the additional questions were also examined. One hundred fifteen participants offered a rea- son why they had chosen to participate. These were coded according to the categories used by Buchanan and Smith (1999a). As in that study, the most common reason reported was curiosity ( $40 \%$ of cases), the next most common being a liking for taking part in tests or surveys $(15 \%)$. A desire to help the research was expressed by $8 \%, 7 \%$ made some reference to a request posted in a newsgroup, $4 \%$ advanced boredom as a reason for participation, and $2 \%$ said that they enjoyed doing tests and surveys. Of the others, $9 \%$ explicitly said "no reason," $6 \%$ made a response combining elements of the other categories, and the remaining $24 \%$ made some other comment. Seventy-eight participants chose to make additional remarks in response to the second question. Most of these related to the stimuli used.

The results obtained here were broadly similar to those obtained using a traditional experimental paradigm (Snyder et al., 1985). However, the effect size is smaller ( $z$ of 1.80 as compared with 2.85 ). There are three main reasons why this might be the case.

The first is differences in experimental materials from those used by Snyder et al. (1985). For instance, were the pictures or personality descriptions insufficiently different?

The second is the difference in experimental procedure. In this study, the participants were asked which of two partners they would theoretically prefer. In Snyder et al.'s study, participants were led to believe that they would actually be going on a date with whoever they chose. This made their choice much more important, with the possible result that they put more thought into it than did the participants in the present study, who simply had to click a button.

The third is the mode of participation. Could the weaker effect be due to the fact that the present study was Internet mediated? Senior, Phillips, Barnes, and David (1999), in a WWW study of facial expression and perceived dominance, similarly found an effect weaker than that in the traditional research on which their work was based (see also Krantz \& Dalal, 2000). If it is the case that Webmediated studies are in some way less powerful, this is a potential problem for Internet research.

One way to test whether or not differences were due to Internet mediation is to replicate the study with the same materials and with the same consequences of decision made, but in a traditional paper-and-pencil format. This was done in Study 2.

\section{STUDY 2}

Study 1 obtained results consistent with theoretical predictions but weaker than those reported by Snyder et al. (1985). Study 2 was performed to test whether this difference in results was due to Internet mediation or some other characteristic of the experimental procedure or materials.

\footnotetext{
Method

Participants. The participants in this study were 102 undergraduate volunteers drawn from Levels 1 and 2 psychology courses.
} 
Three failed to answer all questions on the SMS-R and were dropped from the sample. The responses of a further 4 ( 2 male, 2 female) indicated that they had been unable to make a sexuality-appropriate response, and another 2 (both male) did not provide the information required to assess this. These were also excluded from analysis, leaving a total of 93 participants ( 35 men and 58 women). Among these, mean age was 22.37 years $(S D=5.87)$, and mean self-monitoring score was $9.93(S D=3.62)$.

Materials and Procedure. The same materials were used as in Study 1 but were printed on paper rather than appearing on the computer screen. Participation occurred in small groups, after normal classes.

For ethical reasons, two changes were made to the procedure. In Study 1, the participants chose between targets of the preferred gender. In Study 2, due to the potentially sensitive nature of this information, it was not possible to ascertain the participants' sexual orientation. Instead, all males were asked to choose a female target, and all females were asked to choose a male target. As in Study 1, the participants were asked whether they were primarily attracted to males or females; however, in this case, they were told that responding to the question was optional (in fact, all but 2 made a response). The participants were then thanked and debriefed.

\section{Results and Discussion}

High and low self-monitors in this sample were identified on the basis of norms derived from this study and the pencil-and-paper sample of Buchanan and Smith (1999b), which was drawn from an equivalent population-a total of 323 participants (including 13 whose sex was not known). In that combined sample, mean selfmonitoring scores of the 74 men $(M=10.60, S D=3.78)$ and the 236 women $(M=9.49, S D=3.43)$ differed significantly $[t(308)=2.36, p<.02]$, necessitating the use of different criteria for each sex. For men, the upper and lower quartiles were approximated by $7(23 \%$ scored 7 or below) and 14 (24.4\% scored 14 or above). For women, the corresponding values were $7(27.5 \%$ scored 7 or below) and 13 (28.4\% scored 13 or above).

These values were then used to identify prototypic high and low self-monitors within the present sample. Twentysix participants ( 13 men and 13 women) were thus classified as high self-monitors, and 26 participants $(9$ men and 17 women) were classified as low self-monitors.

A similar $z$ test to that used in Study 1 indicated that the proportions of high and low self-monitors choosing the physically attractive target did not differ at all from the proportions choosing the less physically attractive target with the more desirable personality: Among both the high and the low self-monitors, 18 participants selected the former and 8 selected the latter $\operatorname{target}(z=0.0$, $n=52, p=.50$, one-tailed).

\section{GENERAL DISCUSSION}

It is apparent that Study 1, an Internet-mediated conceptual replication of Snyder et al.'s (1985) work, produced results consistent with the traditional study on which it was based. However, the weaker effect size raised the possibility that Internet studies may in some way be weaker at detecting psychological phenomena. The results of Study 2, a pencil-and-paper replication of Study 1, suggest, however, that this is not the case: Study 2 failed to detect any effect whatsoever. This implies (1) that the present paradigm produced weaker results than Snyder et al.'s for some reason other than the fact of Internet mediation (a good candidate for this reason is the likely consequences of the choice participants were required to make) and (2) that an Internet-mediated version of the current paradigm detected an effect that a paper-andpencil version did not.

For present purposes, the latter point is most important: The critical question now is why the results of Studies 1 and 2 differed. The question may be addressed by considering another difference in the data produced by the two studies. When one considers the choices made by all participants, not just those classified as high or low self-monitors, of all 320 participants who chose between the targets in Study 1,151 chose the more physically attractive target and 169 chose the target with the more desirable personality. Of the 93 who were able to make an appropriate choice in Study 2, 57 chose the former target and 36 chose the latter target. A chi-square test for independence indicated that the frequencies of each choice differed significantly across the two studies $\left[\chi^{2}(1, N=413)\right.$ $=5.73, p<.025]$. Irrespective of their self-monitoring status, the participants in Study 2 were more likely to choose the more physically attractive target. Why?

There are two main candidates for causes of differences between these studies. The first is the interface (Web browser vs. paper questionnaire) through which people participated. The second is the nature of the sample used in each study - the Internet sample is more heterogeneous in terms of age, sexuality, and probably other characteristics.

Buchanan (2000) has suggested that Internet samples with desired profiles may be obtained by recruiting large samples and using demographic data to select a subsample with a composition similar to the population of interest. Using this technique, it may be possible to disentangle the two confounded factors by identifying within the Internet sample (henceforth described as Sample 1) a subsample similar to the sample used in Study 2 (Sample 2): This would result in sets of data that differed only in interface, not sample composition (obviously, we can assess similarity only in terms of characteristics we have data about).

A subset of the data acquired in Study 1 was therefore used to create a new Internet sample, Sample 3. To create this third sample, $95 \%$ confidence intervals for mean age and self-monitoring scores in Sample 2 were calculated. Any Internet respondents who fell within these ranges (approximated by 11-34 for age and 3-17 for selfmonitoring score) and who also met the criteria of being predominantly attracted to the opposite sex (like all Sample 2 members included in analysis) and having made a choice between the two targets were included in Sample 3.

Sample 3 comprised 106 individuals ( 32 women, 74 men). Mean age was 25.18 years $(S D=4.18)$, and mean self-monitoring score was $9.61(S D=3.49)$. Of these, 65 chose the more physically attractive target and 41 
chose the target with the more desirable personality. A chi-square test for independence indicated that the frequency of each choice made by Samples 2 and 3-which were similar in all respects other than mode of experimentation- did not differ $\left[\chi^{2}(1, N=199)=0.00002\right.$, $p>$.99]. These data are summarized in Table 1 .

On the basis of this post hoc analysis, I would tentatively suggest that differences in the results obtained in Studies 1 and 2 are a function of sampling, not mode of experimentation. Had Study 2 used a sample with a similar composition to Sample 1, the same phenomena might well have been observed. This conclusion must be qualified by the fact that, given the modest size of Sample 2, the issue of statistical power is a concern here: It may have been that the sample size was simply too small to detect an effect of the size observed in Study 1. However, it seems unlikely (given the observed $z$ of zero) that a significant effect would be found in Study 2 even if the sample size were much greater.

The findings of Study 1 seem to demonstrate that the effect described by Snyder et al. (1985) occurs in wider samples than those used in the original research. However, the discrepancy between the findings of Studies 1 and 2 , in terms of both the effect of self-monitoring and overall frequency of target choice, suggests that characteristics other than self-monitoring are likely to impact on interpersonal attraction.

This suggestion is reinforced by the observation in Study 1 that low self-monitors attracted to women attached more weight to personality than to appearance in potential partners. This is entirely consistent with the hypotheses previously advanced and the findings obtained in laboratory settings with heterosexual male samples. However, other groups may not behave in the same way. For instance, among the low self-monitors attracted to men, the proportions choosing each target did not differ significantly $(z=-0.22, n=21, p>.83)$. Due to the small sample size and resulting low statistical power, it would be unwise to make too much of this result. However, the contrast with the pattern observed for low selfmonitors attracted to women does suggest that sexuality and self-monitoring (no doubt among many other factors) interact as moderators of the determinants of attraction.

Table 1

Characteristics of the Three Samples

\begin{tabular}{lccc}
\hline & \multicolumn{3}{c}{ Sample } \\
\cline { 2 - 4 } & 1 & 2 & 3 \\
\hline Total $N$ & 320 & 93 & 106 \\
$n$ (male) & 183 & 35 & 74 \\
$n$ (female) & 137 & 58 & 32 \\
Mean age $(S D)$ & $31.54(10.0)$ & $22.37(5.87)$ & $25.18(4.18)$ \\
Mean SM score $(S D)$ & $9.20(3.76)$ & $9.93(3.62)$ & $9.61(3.49)$ \\
$n$ choosing attractive face & 151 & 57 & 65 \\
$n$ choosing less attractive & 169 & 36 & 41 \\
$\chi^{2}$ test of independence & & & .00002 \\
$\quad$ from Sample 2 & $5.73^{*}$ & - & \\
${ }^{*} p<.05$. & & &
\end{tabular}

As previously mentioned, the Internet facilitates recruitment of samples from the appropriate populations in sufficient numbers to make exploration of such issues easier than would otherwise be the case (cf. Smith \& Leigh, 1997). The present research demonstrates that it is indeed possible to recruit members of such groups and, furthermore, to tailor experimental materials to particular participants (presentation of a sexuality-appropriate target, which was not possible in Study 2).

It would also seem to provide further evidence for the construct validity of the Internet-mediated version of the SMS-R. While comparison with Study 2 highlights the importance of sampling issues, the findings of Study 1 provide support for the suggestion (e.g., Krantz \& Dalal, 2000) that Internet-mediated research methods can tap the same psychological phenomena as traditional laboratory studies.

\section{REFERENCES}

Banyard, P., \& Hunt, N. (2000). Reporting research: Something missing? The Psychologist, 13, 68-71.

Birnbaum, M. H. (1999). Testing critical properties of decision making on the Internet. Psychological Science, 10, 399-407.

Birnbaum, M. H. (2000). SurveyWiz and FactorWiz: JavaScript Web pages that make HTML forms for research on the Internet. Behavior Research Methods, Instruments, \& Computers, 32, 339-346.

BuCHANAN, T. (2000). Potential of the Internet for personality research. In M. H. Birnbaum (Ed.), Psychological experiments on the Internet (pp. 121-140). San Diego: Academic Press.

BuchanAN, T., \& SmITH, J. L. (1999a). Research on the Internet: Validation of a World-Wide Web mediated personality scale. Behavior Research Methods, Instruments, \& Computers, 31, 565-571.

Buchanan, T., \& Smith, J. L. (1999b). Using the Internet for psychological research: Personality testing on the World-Wide Web. British Journal of Psychology, 90, 125-144.

Davis, R. N. (1999). Web-based administration of a personality questionnaire: Comparison with traditional methods. Behavior Research Methods, Instruments, \& Computers, 31, 572-577.

DeBono, K. G., \& SNydeR, M. (1989). Understanding consumer decision-making processes: The role of form and function in product evaluation. Journal of Applied Social Psychology, 19, 416-424.

GANGeSTAD, S. W., \& SNYDER, M. (1985). "To carve nature at its joints": On the existence of discrete classes in personality. Psychological Review, 92, 317-340.

Gangestad, S. W., \& Snyder, M. (1991). Taxonomic analysis redux: Some statistical considerations for testing a latent class model. Journal of Personality \& Social Psychology, 61, 141-146.

GLICK, P. (1985). Orientations toward relationships: Choosing a situation in which to begin a relationship. Journal of Experimental Social Psychology, 21, 544-562.

Glick, P., DeMorest, J. A., \& Hotze, C. A. (1988). Self-monitoring and beliefs about partner compatibility in romantic relationships. Personality \& Social Psychology Bulletin, 14, 485-494.

Gonzales, M. H., \& MEyers, S. A. (1993). "Your mother would like me": Self-presentation in the personals ads of heterosexual and homosexual men and women. Personality \& Social Psychology Bulletin, 19, 131-142.

Hewson, C. M., Laurent, D., \& Vogel, C. M. (1996). Proper methodologies for psychological and sociological studies conducted via the Internet. Behavior Research Methods, Instruments, \& Computers, 28, 186-191.

Jolnson, A. N. (1998). Causes and implications of disinhibited behavior on the Net. In J. Gackenbach (Ed.), Psychology of the Internet (pp. 43-60). New York: Academic Press.

JoINSON, A. N. (1999). Social desirability, anonymity, and Internet-based 
questionnaires. Behavior Research Methods, Instruments, \& Computers, 31, 433-438.

Joinson, A. N., \& Buchanan, T. (in press). Doing educational psychology research on the Internet. In C. Wolfe (Ed.), Teaching and learning on the World Wide Web. San Diego: Academic Press.

Krantz, J. H., Ballard, J., \& SCher, J. (1997). Comparing the results of laboratory and World-Wide Web samples on the determinants of female attractiveness. Behavior Research Methods, Instruments, \& Computers, 29, 264-269.

KrantZ, J. H., \& Dalal, R. (2000). Validity of Web-based psychological research. In M. H. Birnbaum (Ed.), Psychological experiments on the Internet (pp. 35-60). San Diego: Academic Press.

Levine, S., ANCilL, R. J., \& RoberTs, A. P. (1988). Assessment of suicide risk by computer-delivered self-rating questionnaire: Preliminary findings. Acta Psychiatrica Scandinavica, 80, 216-220.

McKenna, K. Y., \& BarGH, J. A. (1998). Coming out in the age of the Internet: Identity "demarginalization" through virtual group participation. Journal of Personality \& Social Psychology, 75, 681-694.

MCNemar, Q. (1946). Opinion-attitude methodology. Psychological Bulletin, 43, 289-374.

MUSCH, J., \& REIPS, U.-D. (2000). A brief history of Web experimenting. In M. H. Birnbaum (Ed.), Psychological experiments on the Internet (pp. 61-87). San Diego: Academic Press.

Pagani, D., \& Lombardi, L. (2000). An intercultural examination of facial features communicating surprise. In M. H. Birnbaum (Ed.), $P s y$ chological experiments on the Internet (pp. 169-194). San Diego: Academic Press.

Pasveer, K. A., \& Ellard, J. H. (1998). The making of a personality inventory: Help from the WWW. Behavior Research Methods, Instruments, \& Computers, 30, 309-313.

Pines, A. M. (1998). A prospective study of personality and gender differences in romantic attraction. Personality \& Individual Differences, 25, 147-157.

ReIPS, U.-D. (1996, October). Experimenting in the World-Wide Web. Paper presented at the 1996 Society for Computers in Psychology Conference, Chicago.

REIPS, U.-D. (2000). The Web experiment method: Advantages, disadvantages, and solutions. In M. H. Birnbaum (Ed.), Psvchological experiments on the Internet (pp. 89-117). San Diego: Academic Press.

Rosenfeld, P., Giacalone, R. A., Knouse, S. B.. Doherty, L. M.. VICINo, S. M., Kantor, J., \& Greaves, J. (1991). Impression management, candor and microcomputer-based organizational surveys: An individual differences approach. Computers in Human Behavior, 7, 23-32.

SchMIDT, W. C. (1997). World-Wide Web survey research: Benefits, potential problems, and solutions. Behavior Research Methods, Instruments, \& Computers, 29, 274-279.
Schwarzer, R., Mueller, J., \& Greenglass, E. (1999). Assessment of perceived self-efficacy on the Internet: Data collection in cyberspace. Anxiety, Stress \& Coping, 12, 145-161.

Senior, C., Phillips, M. L., Barnes, J., \& David, A. S. (1999). An investigation into the perception of dominance from schematic faces: A study using the World-Wide Web. Behavior Research Methods, Instruments, \& Computers, 31, 341-346.

SiEver, M. D. (1994). Sexual orientation and gender as factors in socioculturally acquired vulnerability to body dissatisfaction and eating disorders. Journal of Consulting \& Clinical Psychology, 62, 252-260.

Smith, M. A., \& Leigh, B. (1997). Virtual subjects: Using the Internet as an alternative source of subjects and research environment. $B e-$ havior Research Methods, Instruments, \& Computers, 29, 496-505.

SNYDER, M. (1974). Self-monitoring of expressive behavior. Journal of Personality \& Social Psychology, 30, 526-537.

SNYDER, M. (1987). Public appearances/private realities. New York: W. H. Freeman.

SNydER, M., Berscheid, E., \& Glick, P. (1985). Focusing on the exterior and the interior: Two investigations of the initiation of personal relationships. Journal of Personality \& Social Psychology, 48, 14271439.

Snyder, M., Berscheid, E., \& Matwychuk, A. (1988). Orientations toward personnel selection: Differential reliance on appearance and personality. Journal of Personality \& Social Psychology, 54, 972-979.

SNYDER, M., \& GANGESTAD, S. W. (1986). On the nature of selfmonitoring: Matters of assessment, matters of validity. Journal of Personality \& Social Psychology, 51, 125-139.

Stones, A., \& PERrY, D. (1997). Survey questionnaire data on panic attacks gathered using the World Wide Web. Depression \& Anxiety, 6, 86-87.

SzABO, A., \& FrenkL, R. (1996). Consideration of research on Internet: Guidelines and implications for human movement studies. Clinical Kinesiology, 50, 58-65.

\section{NOTE}

1. Note that the makeup of this sample cannot be considered representative of the Internet population in general: Deliberate attempts were made to recruit people of different genders and sexualities. The relatively low number of heterosexual women, for instance, should not be taken as evidence that they are rare among Internet users.

(Manuscript received June 14, 1999; revision accepted for publication July 30,2000 .) 